\title{
Wild Medicinal Fungi: Phallus Impudicus-induced Telomere Damage Triggers p21/p53 and p16- dependent Cell Cycle Arrest and Drives to Male Fertility Reduction in Vitro
}

\section{Przemyslaw Solek ( $\sim$ pp.solek@gmail.com )}

Faculty of Biotechnology https://orcid.org/0000-0002-6194-0042

Nataliya Shemedyuk

Stepan Gzhytskyj National University of Veterinary Medicine and Biotechnologies Lviv

Anastasiya Shemedyuk

Ivan Franko National University of Lviv

Ewa Dudzinska

Uniwersytet Medyczny w Lublinie

Marek Koziorowski

Uniwersytet Rzeszowski

\section{Research}

Keywords: Phallus impudicus, GC-1 spg\& GC-2 spd, men fertility reduction, telomere damage, apoptosis

Posted Date: July 24th, 2020

DOI: https://doi.org/10.21203/rs.3.rs-47590/v1

License: (c) (1) This work is licensed under a Creative Commons Attribution 4.0 International License.

Read Full License 


\section{Abstract}

The multifunctional characteristics of Phallus impudicus extract encourages to conduct research for its probable potential in medical applications. Well, science is constantly seeking new evidence for the biological activity of extracts of natural origin. Drugs of natural origin should not cause any side effects on the physiological functions of the human body; however, this is not always successful. In this study, we used in vitro approach to evaluate the toxicity of alcohol Phallus impudicus extract on spermatogenic cells. We show, for the first time, cytotoxic properties of Phallus impudicus treatment associated with a decrease in cellular metabolic activity, dysregulation of redox homeostasis and impairment of selected antioxidant cell protection systems. As a consequence, p53/p21- and p16-mediated cell cycle arrest followed by $\mathrm{p}-27$ activation is initiated. The observed changes were associated with telomere shortening and numerous DNA damage at the chromosome ends (altered expression pattern of TRF1 and TRF2 proteins), as well as upregulation of cleaved caspase- 3 with a decrease in $\mathrm{Bcl}-2$ synthesis, suggesting induction of apoptotic death. Therefore, these results provide molecular evidence for mechanistic pathways and novel adverse outcomes linked to the Phallus impudicus treatment towards men's health and fertility reduction.

\section{Introduction}

Nowadays, in medical practice, more and more attention is paid to the creation of medications based on natural raw materials. Scientists are constantly seeking for natural substances with beneficial adaptogen, antioxidant, immunomodulator or antitumor properties. In contrast to drugs produced via chemical synthesis, those of natural origin should not cause any side effects on the physiological functions of the human body. Research data suggested that extract from Phallus impudicus may be a promising source of this type of safe drugs (Petrova et al. 2008; Chaturvedi et al. 2018; Wasser 2002; Meng et al. 2016). In fact, in non-traditional (alternative) medicine, water and alcoholic extracts from fresh or dry fungi are widely used. This may be related to a broad spectrum of action in the treatment of cardiovascular diseases, malignant tumors, sexual weakness, and even during chemo or radiation therapy to prevent metastases and relapse of oncological diseases (Valverde et al. 2015; Jin et al. 2016).

Among biologically active components of Phallus impudicus, there are polysaccharides, peptides, phospholipids, glucans, polyphenols, vitamins, unsaturated fatty acids or chitin. Moreover, the presence of active compounds is characterized by antioxidant, anti-inflammatory, anticancer or antibacterial effects. The development of safe, more effective and controlled therapeutics based on the raw extract or active compound of Phallus impudicus requires more detailed information on its potentially toxic effects in clinical practice (Wang et al. 2014; Miles and Chang 1997).

Eliminating a problem associated with the reproductive process, also in the molecular aspect, will increase male reproductive performance. Without a doubt, one of the main factors determining the appropriate fertility is the proper course of the spermatogenesis process. Disruption of this process through various environmental factors results in a decrease in the biological value of spermatozoa, which 
ultimately reduces fertility. Factors that negatively affect the course of spermatogenesis are, among others, various types of pharmacological agents, including those of natural origin (Solek et al. 2018b).

Phallus impudicus in traditional medicine is used to treat and prevent the functioning of the male reproductive system. Due to this fact and the lack of literature data, we focused our attention on potential toxic effects of Phallus impudicus extract on spermatogenic cells (GC-1 spg, GC-2 spd) in mechanistic terms. The main aim of the present study was to investigate the stress-related effects of extract in the terms of cellular and biochemical features in vitro particularly in the area of mechanistic toxicology.

\section{Materials And Methods}

Phallus impudicus extract preparation

Phallus impudicus alcohol extract was prepared by the infusion of raw material (fruit bodies of mushrooms Phallus impudicus) with $40 \%$ ethanol as the extractant. The ratio of the extracted substance to extractant was 1:4 (raw mass: volume, g:mL). The steep took place for 14 days at a temperature of $20-22^{\circ} \mathrm{C}$ in the dark. The prepared extract was sterilized using nylon membrane filters (pore size $0.45 \mu \mathrm{m}$ ). The extract was stored in tightly sealed dark containers in a refrigerator at $4{ }^{\circ} \mathrm{C}$ for later use. For preparation of $1 \%$ Phallus impudicus extract, $2.5 \cdot 10^{-3} \mathrm{~g} / \mathrm{mL}$ raw material of fruit bodies, $2 \%-5 \cdot 10^{-}$ ${ }^{3} \mathrm{~g} / \mathrm{mL}, 3 \%-7.5 \cdot 10^{-3} \mathrm{~g} / \mathrm{mL}$, was used.

In vitro culture of spermatogenic cells

Both cell lines (GC-1 spg and GC-2 spd) were obtained from the American Type Culture Collection (ATCC, Manassas, Virginia, USA), grown in DMEM with $4.5 \mathrm{~g} / \mathrm{L}$ glucose and $1 \mathrm{mM}$ sodium pyruvate (without Lglutamine), supplemented with $10 \%$ fetal bovine serum and antibiotic mix solution $(100 \mathrm{U} / \mathrm{mL}$ penicillin, $0.1 \mathrm{mg} / \mathrm{mL}$ streptomycin, $29.2 \mathrm{mg} / \mathrm{mL}$ L-glutamine) at $37^{\circ} \mathrm{C}$ in $5 \% \mathrm{CO}_{2}$ humidified incubator. Cells were passaged every 3-4 days by trypsinization. Cells were seeded at a constant density of $1.0 \times 10^{3} / \mathrm{cm}^{2}$ for all experiments and allowed to attach for several hours. For experiments, cells were treated with $1-3 \%$ Phallus impudicus extract prepared by direct dilution in cell culture medium, left for $48 \mathrm{~h}$ unless otherwise mentioned and then, analyzed. All experiments were repeated independently at least in triplicates.

\section{Cell Viability Assay}

Cell viability was assessed by an MTT assay described elsewhere (Mytych et al. 2017). For MTT, the cell cultures were treated with Phallus impudicus extract in 1-3\% concentration for $48 \mathrm{~h}$. Then, MTT solution $(5 \mathrm{mg} / \mathrm{mL}$ ) was added, incubated for 4 hours to allow cells to metabolize MTT to formazan and then, formed violet crystals were dissolved in DMSO. After shaking at RT, the absorbance was determined at wavelengths of 590 and $620 \mathrm{~nm}$ (measurement and reference wavelengths, respectively). Cell viability was shown as a percentage of non-treated control cells (considered as $100 \%$ ). 


\section{Morphological Alterations}

The morphological alterations of spermatogenic cells following the incubation with $3 \%$ Phallus impudicus extract were visualized using an inverted light microscope Zeiss Axiovert 40 CFL equipped with a Zeiss AxioCam MRm3 camera (Carl Zeiss, Germany). Photographic images were captured after 48 and $96 \mathrm{~h}$ using phase contrast and AxioVs40 V 4.8.1.0 software.

\section{Intracellular Redox Balance}

To detect intracellular superoxide (02--), nitric oxide (NO) and reduced glutathione (thiol) levels, both cell lines were loaded with D-PBS supplemented with fluorogenic probes: dihydroethidium (DHE), 4-amino-5 methylamino-2',7'-difluorofluorescein diacetate (DAF-FM) and thiol (Thiol Tracker Violet) (each at a final concentration of $5 \mu \mathrm{M}$ ) for $30 \mathrm{~min}$ at $37^{\circ} \mathrm{C}$. Signal detection and fluorescence intensity were measured with InCell Analyzer 2000 and presented as relative fluorescence units (\% of control). A minimum of 1000 cells was counted in each sample.

\section{Progression Through The Cell Cycle And Micronucleus Formation}

Spermatogenic cells were treated with 3\% Phallus impudicus extract for $48 \mathrm{~h}$, washed once with PBS and stained with Hoechst 33342 solution (nuclei: final concentration $1 \mu \mathrm{g} / \mathrm{mL}$ ) and Calcein-AM (cytoplasm: final concentration $0.3 \mu \mathrm{g} / \mathrm{mL}$ ) for $10 \mathrm{~min}$. Assessment of DNA content was performed manually by integrating the nuclear fluorescence with the use of ImageJ software and DNA Cell cycle plug-in. Fluorescent images were captured using InCell Analyzer 2000. DNA content was used as parameter categorizing cells into three groups, G0-G1, S, and G2/M phases. Also, the measurement of micronuclei formation was performed using InCell Analyzer 2000 module on images taken after cell cycle assessment. A minimum of 1000 cells was counted in each sample.

\section{Western Blotting}

Proteins of interest were visualized by Western Blotting according to Solek et al 2018 (Solek et al. 2018a). Briefly, total cell extracts were prepared by homogenization in RIPA buffer.The protein concentration was determined using BCA kit (Pierce Protein Biology, Thermo Fisher Scientific). Equal amounts of proteins $(30 \mu \mathrm{g})$, as determined by the BCA assay, were resolved during 10\% SDS-PAGE electrophoresis and electroblotted onto PVDF membranes (Thermo Fisher Scientific), Membranes were blocked in 1\% BSA for $1 \mathrm{~h}$ and then, probed with primary antibody for $24 \mathrm{~h}$ at $4{ }^{\circ} \mathrm{C}$, followed by incubation with secondary antibody and visualization. 
Antibodies used were: anti-ß-actin (\#PA1-16889), anti-p16 (\#PA5-16639), anti-p21 (\#PA5-701151), antip27 (\#PA5-13254), anti-p53 (\#700439), anti-phospho-NF-kB (\#PA5-37658), anti-TRF1 (\#MA1-46089), anti-TRF2 (\#MA1-41001), (Thermo Fisher Scientific), anti-Bcl-2 (\#sc-7382) (Santa Cruz), anti-active caspase 3 (\#NB100-56113) (Novus Biologicals). Secondary HRP-conjugated: anti-mouse (\#A9044) and anti-rabbit (\#A0545) (Sigma).

The immunocomplexes were visualized with chemiluminescent substrate (BioRad, USA) using a Fusion Fx7 system (Viber Lourant) according to the provided instructions. Densitometry analysis was conducted using GelQuantNET software, while $\beta$-actin was used for normalization of protein synthesis data.

\section{Data Analysis, Statistical Handling Of Data And Graphical Production}

One-way analysis of variance (ANOVA) was performed, followed by a Dunnett's post-test for significance between treatment groups using GraphPad Prism ver. 6.0. Statistical significance was set at $p<0.05$. Different labels are: ${ }^{*}, p<0.05 ; * \star, p<0.01 ; * \star *, p<0.001$. Asterisks $\left.{ }^{*}\right)$ indicate the comparison between vehicle-treated (CTRL) and Phallus impudicus extract-treated cells. Data are reported as means \pm standard deviation from at least three independent experiments. Adobe Photoshop CC was used to process images and to design figures.

\section{Result}

Effects of Phallus impudicus-treatment on spermatogenic cells proliferation and morphology

In order to identify toxic doses $\mathrm{f}$ Phallus impudicus (PI), GC-1 spg and GC-2 spd cells were treated with various concentrations of PI extract, ranged from 1 to $3 \%$. Cells were incubated for $48 \mathrm{~h}$, then the cell metabolic activity was calculated by MTT analysis. We observed a progressive reduction in metabolic activity in a dose-dependent manner. Moreover, the proliferation rate of PI-treated cells revealed a similar trend in both cell lines tested. Interestingly, the GC-2 spd cells seem to be more resistant to the extract exposure (statistically insignificant results). Based on the results obtained, we selected a toxic concentration of $3 \%$ Phallus impudicus extract for all further experimental procedures (marked with a red frame) (Fig. 1a-b).

We further analyzed whether the cells tested were abnormal in shape or unequal in size. Control cells were characterized by a normal epithelial, irregular shape with uniformly granular cytoplasm and good adhesion to the culture flask. In turn, Pl-treated cells showed vacuolization of the cytoplasm and partial loss of adhesion. Moreover, we observed a robust shape change due to contraction under timedependent. The number of cells also seems to decrease, which confirms MTT results. The observed differences were even more pronounced after 96 hours of incubation. (Fig. 2). 


\section{Free Radicals And Antioxidants}

Mitochondrially-derived ROS/RNS can mediate redox balance and, more importantly, indicate mitochondrial dysfunction. Here, we observed ROS overproduction and a constant level of intracellular NO in all experimental sets. At the same time, the enzymatic antioxidant cellular defense system was activated (Fig. 3a-c). One of the major consequences of set in motion ROS-induced stress signaling pathway may be cell cycle arrest related to micronuclei formation as a genotoxic endpoint marker.

\section{Cell cycle profile changes and micronuclei formation}

Continuing the above, we evaluated the effect of Phallus impudicusextract on the cell cycle distribution of both cell lines tested.We found that extract treatment resulted in cell cycle arrests in the G0-G1 phase, thus inhibiting cell proliferation. At the same time, the number of cells in the $\mathrm{G} 2$ phase was reduced (Fig. 4 a). Further, ROS overproduction can directly target DNA. For this reason, we evaluated the frequency of micronuclei formation (MN) related to Phallus impudicus extract treatment. As expected, we observed a significant increase in their production no matter from the experimental system under study (Fig. 4 b-c).

\section{Protein Synthesis Study}

The final stage of the research was the mechanistic assessment of intracellular signaling pathways. We analyzed the level of protein synthesis associated with cellular and biochemical stress-related effects in vitro. We observed the upregulation of phosphorylation of nuclear factor NF-KB in GC-1 spg cells exposed to Phallus impudicus extract treatment for $48 \mathrm{~h}$ (Fig. 5a-b). Further, p16 protein synthesis was increased only in the case of GC-2 spd cells (48 and $96 \mathrm{~h}$ incubation) (Fig. 5a, c). At the same time p21, p27 and p53 protein synthesis were clearly reduced with the exception of GC-2 spd $48 \mathrm{~h}$ (p27) and GC-1 spg 48 and $96 \mathrm{~h}$ (p53) (Fig. 5a, d-f). Consecutively, quantitative immunoblot analysis showed an increased pool of TRF1 and TRF2 after $48 \mathrm{~h}$ (both lines) with a simultaneous decrease after $96 \mathrm{~h}$ (both lines again) excluding 48 h GC-1 spg (Fig. 5a, g-h). Finally, we noticed a significant increase in the level of active casp3 executive protein synthesis with a concomitant drop in Bcl-2 regulating apoptosis (Fig. 5a, i-j).

\section{Discussion}

The Phallus impudicus is a common and widely distributed fungi in Europe and North America. In addition, its characteristic appearance and smell make it one of the most recognizable of this species. Surprisingly, immature fruiting bodies are edible and are regarded as delicacies in some countries (Pudil et al. 2014). Numerous studies provide evidence on the biological activity of Phallus impudicus extract components, including polysaccharides, polyphenols, vitamins, hydrocarbons, alcohols, aldehydes, ketones, acids, and others (Chan et al. 2009; Legentil et al. 2015). Moreover, the bioactive properties of individual components have also been described in detail (Sari et al. 2017; Volman et al. 2010). However, it is not clear whether the observed immune- and antitumor effects are the result of a single action or the sum of the effects of all ingredients in synergy. 
In this study, we successfully established dose-dependent inhibition of spermatogenic cells metabolic activity related to Phallus impudicus treatment. In detail, we observed more pronounced decreases in the B-type spermatogonia cell proliferation. Our findings indicate that this type of cells is more sensitive to the Phallus impudicus extract stimulation. The obtained result may be associated with various types of cells tested and their other physiological functions. This is consistent with other reports, which demonstrate that different fungal extracts inhibit cell proliferation in a cell-specific dependent manner at both short- and long-term (Ramos et al. 2016; Wu et al. 2014). Furthermore, fungi extracts have an antiproliferation effect on tumors through various intracellular signaling pathways. Based on these findings, it has been hypothesized that extracts can be considered as potential anticancer agents (Wu et al. 2014).

Consequently, negative morphological changes may explain also a decrease in cell proliferation. Exposure of spermatogenic cells to Phallus impudicus extract resulted in significant alterations related probably to a decrease in cell metabolic activity or even cellular death. Changes in cell shape and plasticity may also be correlated with impairment of cell adhesion dynamics, which was also observed in this study. Some others noted also decrease cell volume and membrane blebbing. The authors indicate that such characteristics occur in the early stage of apoptosis (Kumari et al. 2018; Ramos et al. 2015).

The first cell physiological response to toxic factors may by the imbalance between cellular reactive oxygen/nitrogen species production and antioxidant defense mechanisms. Oxidative or nitrosative stress can be triggered by mitochondrial dysfunction or antioxidant system impairment (Nita and Grzybowski 2016). Indeed, firstly we observed abnormalities in cell metabolic activity and secondly ROS overproduction, while the RNS level remained unaffected. The effect was more pronounced for GC-1 spg cells and confirms the MTT results. These observations were associated with the activation of the free radical scavenger mechanisms (reduced glutathione), suggesting that Phallus impudicus extract may activate the first line of defense against free radical damage. One of the components of Phallus impudicus extract are flavonoids with free radical scavenging activity (Mau et al. 2002; Barros et al. 2009). Others also report a reduction in reactive oxygen species production by a wide range of mushrooms (Sanchez 2017). There is no doubt that ROS overproduction has a destructive effect on the mitochondria function and other cell components. Here, we confirmed that intracellular redox imbalance promoted cell cycle progression with simultaneous DNA damage. We noted G0-G1 cell cycle arrest and a significant increase in micronuclei formation of both cell lines tested. Literature confirms cell cycle arrest in the G2/M phase, proliferation inhibition in vitro (Xu et al. 2017; Jafaar et al. 2014), as well as cell death (Legentil et al. 2015; Xu et al. 2016) associated with Phallus impudicus extract components treatment. Flavonoids, flavones, and flavonols may be responsible for observed cytotoxic effects (Carrasco-Torres et al. 2017; Srivastava et al. 2016; Wang et al. 2015).

Finally, we investigated the mechanistic pathways involved in the regulation of cellular response to cytotoxic and genotoxic events induced by Phallus impudicus extract treatment. The activation of the NFKB transcription factor was correlated with ROS overproduction and initiated a sequence of cell biological responses. Data suggest that the mechanism of genotoxicity of flavonoids is associated with their 
impact on the NF-KB, Akt and MAPK signaling pathways. Furthermore, the toxic effects of flavonoids are highly related to the topoisomerase II or 5-reductase enzyme inhibition or the formation of free radicals (Bandele and Osheroff 2007; Snyder and Gillies 2002). Interestingly, activation of NF-KB is considered as a marker of apoptosis inhibition. Our findings show that Phallus impudicus extract antiproliferative activity was due to p53-dependent cell cycle arrest in G0-G1 mediated by p21. Therefore, accumulated free radicals or DNA damage leads to p16- and p-27 activation potentially contributing to cell cycle arrest. Others also reported that fungi extract treatment resulted in cell cycle arrest at the G1 phase and the process might be mediated through up-regulation of p21/Waf1 or p27 and p53, down-regulation of D1, CDK2, CDK4 cyclins and inhibited phosphorylation of Rb and E2F1 (Wu et al. 2012; Lee et al. 2015). In many cases, the irreversible cell cycle arrest can also be caused by telomeric DNA damage. Importantly, the telomere regions are particularly sensitive to oxidative stress and impaired natural antioxidant mechanisms. Of note, we observed an increase in TRF1 and TRF2 protein synthesis in both cell lines tested, which was probably associated with telomere shortening and numerous DNA damage at the chromosome ends. Previous reports found that natural products reduce the telomerase activity suggesting that they can be utilized as a functional food in cancer prevention (Ganesan and Xu 2017). In turn, it was reported that anti-tumor properties are associated with polysaccharides, glucomannans, which ultimately may lead to apoptosis by activation of proapoptotic protein and caspase-dependent pathways (Wasser 2002). Major proteins involved in the regulation of programmed cell death are caspases. Here, we observed a clear relationship between caspase-3/Bcl-2, more specifically a significant upregulation of cleaved caspase-3 with a simultaneous decrease in Bcl-2 synthesis. Similar observations were done by other researchers (Lee et al. 2009; Haque and Islam 2019). In addition, apoptosis induction was related to increased pro-apoptotic Bax protein expression, inhibition of Bcl-2, and activation of key mediators of signaling in fungi - p38 MAPKs (Chen et al. 2010).

In conclusion, the biological activity of compounds of Phallus impudicus extract suggests a wide potential for medical applications. We indicate that further molecular targets involved in the anticancer activity should be considered. In turn, Phallus impudicus treatment contributes to the impairment of spermatogenesis leading to reduced quality of spermatogenic cells in a cell-specific manner. Notably, we provide molecular evidence for mechanistic pathways and novel adverse outcomes linked to the Phallus impudicus treatment towards men's health and fertility reduction.

\section{Declarations}

\section{Author Contributions:}

PS: conceived and performed the experiments, analyzed the data, carried out data interpretation, designed the figures, contributed reagents/materials/analysis tools, original draft preparation, funding acquisition; NS: conceivedand performed the experiments, contributed materials; AS: performed the experiments; ED: performed the experiments;MK:carried out datainterpretation, supervised the work.

All authors read and approvedthe final version of this manuscript. 


\section{Funding:}

This study was supported in part by the Grant for Young Scientist, University of Rzeszow, Poland (grant no. PZBSiNP/I/2015).

\section{Competing interests:}

The authors declare that they have no competing interests.

\section{Adherence to national and international regulations:}

Not applicable.

\section{Ethics approval and consent to participate:}

Not applicable.

\section{Consent for publication:}

Not applicable.

\section{Adherence to national and international regulations:}

Not applicable.

\section{References}

Bandele OJ, Osheroff N (2007) Bioflavonoids as poisons of human topoisomerase II alpha and II beta. Biochemistry 46 (20):6097-6108. doi:10.1021/bi7000664

Barros L, Duenas M, Ferreira IC, Baptista P, Santos-Buelga C (2009) Phenolic acids determination by HPLC-DAD-ESI/MS in sixteen different Portuguese wild mushrooms species. Food Chem Toxicol 47 (6):1076-1079. doi:10.1016/j.fct.2009.01.039

Carrasco-Torres G, Baltierrez-Hoyos R, Andrade-Jorge E, Villa-Trevino S, Trujillo-Ferrara JG, VasquezGarzon VR (2017) Cytotoxicity, Oxidative Stress, Cell Cycle Arrest, and Mitochondrial Apoptosis after Combined Treatment of Hepatocarcinoma Cells with Maleic Anhydride Derivatives and Quercetin. Oxid Med Cell Longev 2017:2734976. doi:10.1155/2017/2734976

Chan GC, Chan WK, Sze DM (2009) The effects of beta-glucan on human immune and cancer cells. J Hematol Oncol 2:25. doi:10.1186/1756-8722-2-25

Chaturvedi VK, Agarwal S, Gupta KK, Ramteke PW, Singh MP (2018) Medicinal mushroom: boon for therapeutic applications. 3 Biotech 8 (8):334. doi:10.1007/s13205-018-1358-0 
Chen YJ, Liu WH, Kao PH, Wang JJ, Chang LS (2010) Involvement of p38 MAPK- and JNK-modulated expression of Bcl-2 and Bax in Naja nigricollis CMS-9-induced apoptosis of human leukemia K562 cells. Toxicon 55 (7):1306-1316. doi:10.1016/j.toxicon.2010.01.024

Ganesan K, Xu B (2017) Telomerase Inhibitors from Natural Products and Their Anticancer Potential. Int J Mol Sci 19 (1). doi:10.3390/ijms19010013

Haque MA, Islam MAU (2019) Pleurotus highking Mushroom Induces Apoptosis by Altering the Balance of Proapoptotic and Antiapoptotic Genes in Breast Cancer Cells and Inhibits Tumor Sphere Formation. Medicina (Kaunas) 55 (11). doi:10.3390/medicina55110716

Jafaar ZM, Litchfield LM, Ivanova MM, Radde BN, Al-Rayyan N, Klinge CM (2014) beta-D-glucan inhibits endocrine-resistant breast cancer cell proliferation and alters gene expression. Int J Oncol 44 (4):13651375. doi:10.3892/ijo.2014.2294

Jin X, Ruiz Beguerie J, Sze DM, Chan GC (2016) Ganoderma lucidum (Reishi mushroom) for cancer treatment. Cochrane Database Syst Rev 4:CD007731. doi:10.1002/14651858.CD007731.pub3

Kumari M, Taritla S, Sharma A, Jayabaskaran C (2018) Antiproliferative and Antioxidative Bioactive Compounds in Extracts of Marine-Derived Endophytic Fungus Talaromyces purpureogenus. Front Microbiol 9:1777. doi:10.3389/fmicb.2018.01777

Lee HS, Kim EJ, Kim SH (2015) Ethanol extract of Innotus obliquus (Chaga mushroom) induces G1 cell cycle arrest in HT-29 human colon cancer cells. Nutr Res Pract 9 (2):111-116. doi:10.4162/nrp.2015.9.2.111

Lee SH, Hwang HS, Yun JW (2009) Antitumor activity of water extract of a mushroom, Inonotus obliquus, against HT-29 human colon cancer cells. Phytother Res 23 (12):1784-1789. doi:10.1002/ptr.2836

Legentil L, Paris F, Ballet C, Trouvelot S, Daire X, Vetvicka V, Ferrieres V (2015) Molecular Interactions of beta-(1-->3)-Glucans with Their Receptors. Molecules 20 (6):9745-9766. doi:10.3390/molecules20069745

Mau JL, Lin HC, Chen CC (2002) Antioxidant properties of several medicinal mushrooms. J Agric Food Chem 50 (21):6072-6077. doi:10.1021/jf0201273

Meng X, Liang H, Luo L (2016) Antitumor polysaccharides from mushrooms: a review on the structural characteristics, antitumor mechanisms and immunomodulating activities. Carbohydr Res 424:30-41. doi:10.1016/j.carres.2016.02.008

Miles P, Chang ST (1997) Mushroom Biology, Concise Basics and Current Developments.

Mytych J, Wos I, Solek P, Koziorowski M (2017) Protective role of klotho protein on epithelial cells upon co-culture with activated or senescent monocytes. Exp Cell Res 350 (2):358-367.

doi:10.1016/j.yexcr.2016.12.013

Page 10/17 
Nita M, Grzybowski A (2016) The Role of the Reactive Oxygen Species and Oxidative Stress in the Pathomechanism of the Age-Related Ocular Diseases and Other Pathologies of the Anterior and Posterior Eye Segments in Adults. Oxid Med Cell Longev 2016:3164734. doi:10.1155/2016/3164734

Petrova RD, Reznick AZ, Wasser SP, Denchev CM, Nevo E, Mahajna J (2008) Fungal metabolites modulating NF-kappaB activity: an approach to cancer therapy and chemoprevention (review). Oncol Rep 19 (2):299-308

Pudil F, Uvira R, Janda V (2014) Volatile compounds in Stinkhorn (Phallus impudicus L. ex Pers.) at Different Stages of Grouwth. European Scientific Journal 10 (9):163-171

Ramos AA, Castro-Carvalho B, Prata-Sena M, Dethoup T, Buttachon S, Kijjoa A, Rocha E (2016) Crude Extracts of Marine-derived and Soil Fungi of the Genus Neosartorya Exhibit Selective Anticancer Activity by Inducing Cell Death in Colon, Breast and Skin Cancer Cell Lines. Pharmacognosy Res 8 (1):8-15. doi:10.4103/0974-8490.171105

Ramos AA, Prata-Sena M, Castro-Carvalho B, Dethoup T, Buttachon S, Kijjoa A, Rocha E (2015) Potential of four marine-derived fungi extracts as anti-proliferative and cell death-inducing agents in seven human cancer cell lines. Asian Pac J Trop Med 8 (10):798-806. doi:10.1016/j.apjtm.2015.09.005

Sanchez C (2017) Reactive oxygen species and antioxidant properties from mushrooms. Synth Syst Biotechnol 2 (1):13-22. doi:10.1016/j.synbio.2016.12.001

Sari M, Prange A, Lelley Jl, Hambitzer R (2017) Screening of beta-glucan contents in commercially cultivated and wild growing mushrooms. Food Chem 216:45-51. doi:10.1016/j.foodchem.2016.08.010

Snyder RD, Gillies PJ (2002) Evaluation of the clastogenic, DNA intercalative, and topoisomerase IIinteractive properties of bioflavonoids in Chinese hamster V79 cells. Environ Mol Mutagen 40 (4):266276. doi:10.1002/em.10121

Solek P, Majchrowicz L, Koziorowski M (2018a) Aloe arborescens juice prevents EMF-induced oxidative stress and thus protects from pathophysiology in the male reproductive system in vitro. Environ Res 166:141-149. doi:10.1016/j.envres.2018.05.035

Solek P, Shemedyuk N, Gorka A, Bilska-Kos A, Shemedyuk A, Koziorowski M (2018b) Male reprotoxicity associated with Sophora japonica treatment: evaluation of cellular and molecular events in vitro. $J$ Physiol Pharmacol 69 (6). doi:10.26402/jpp.2018.6.11

Srivastava S, Somasagara RR, Hegde M, Nishana M, Tadi SK, Srivastava M, Choudhary B, Raghavan SC (2016) Quercetin, a Natural Flavonoid Interacts with DNA, Arrests Cell Cycle and Causes Tumor Regression by Activating Mitochondrial Pathway of Apoptosis. Sci Rep 6:24049. doi:10.1038/srep24049

Valverde ME, Hernandez-Perez T, Paredes-Lopez O (2015) Edible mushrooms: improving human health and promoting quality life. Int J Microbiol 2015:376387. doi:10.1155/2015/376387 
Volman JJ, Mensink RP, van Griensven LJ, Plat J (2010) Effects of alpha-glucans from Agaricus bisporus on ex vivo cytokine production by LPS and PHA-stimulated PBMCs; a placebo-controlled study in slightly hypercholesterolemic subjects. Eur J Clin Nutr 64 (7):720-726. doi:10.1038/ejcn.2010.32

Wang W, Li Y, Wang H, Zu Y (2014) Differences in the activities of eight enzymes from ten soil fungi and their possible influences on the surface structure, functional groups, and element composition of soil colloids. PLoS One 9 (11):e111740. doi:10.1371/journal.pone.0111740

Wang Y, Han A, Chen E, Singh RK, Chichester CO, Moore RG, Singh AP, Vorsa N (2015) The cranberry flavonoids PAC DP-9 and quercetin aglycone induce cytotoxicity and cell cycle arrest and increase cisplatin sensitivity in ovarian cancer cells. Int J Oncol 46 (5):1924-1934. doi:10.3892/ijo.2015.2931

Wasser SP (2002) Medicinal mushrooms as a source of antitumor and immunomodulating polysaccharides. Appl Microbiol Biotechnol 60 (3):258-274. doi:10.1007/s00253-002-1076-7

Wu G, Qian Z, Guo J, Hu D, Bao J, Xie J, Xu W, Lu J, Chen X, Wang Y (2012) Ganoderma lucidum extract induces G1 cell cycle arrest, and apoptosis in human breast cancer cells. Am J Chin Med 40 (3):631-642. doi:10.1142/S0192415X12500474

Wu HT, Lu FH, Su YC, Ou HY, Hung HC, Wu JS, Yang YC, Chang CJ (2014) In vivo and in vitro anti-tumor effects of fungal extracts. Molecules 19 (2):2546-2556. doi:10.3390/molecules19022546

Xu H, Zou S, Xu X (2017) The beta-glucan from Lentinus edodes suppresses cell proliferation and promotes apoptosis in estrogen receptor positive breast cancers. Oncotarget 8 (49):86693-86709. doi:10.18632/oncotarget. 21411

Xu H, Zou S, Xu X, Zhang L (2016) Anti-tumor effect of beta-glucan from Lentinus edodes and the underlying mechanism. Sci Rep 6:28802. doi:10.1038/srep28802

\section{Figures}


a)
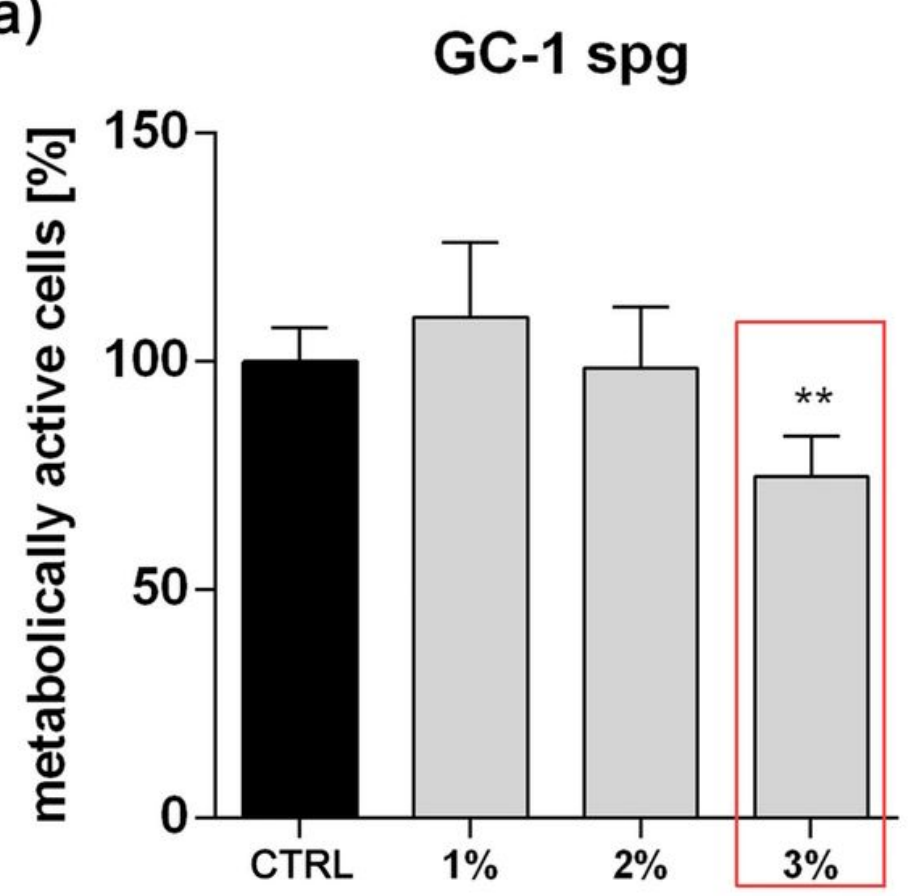

Phallus impudicus b)

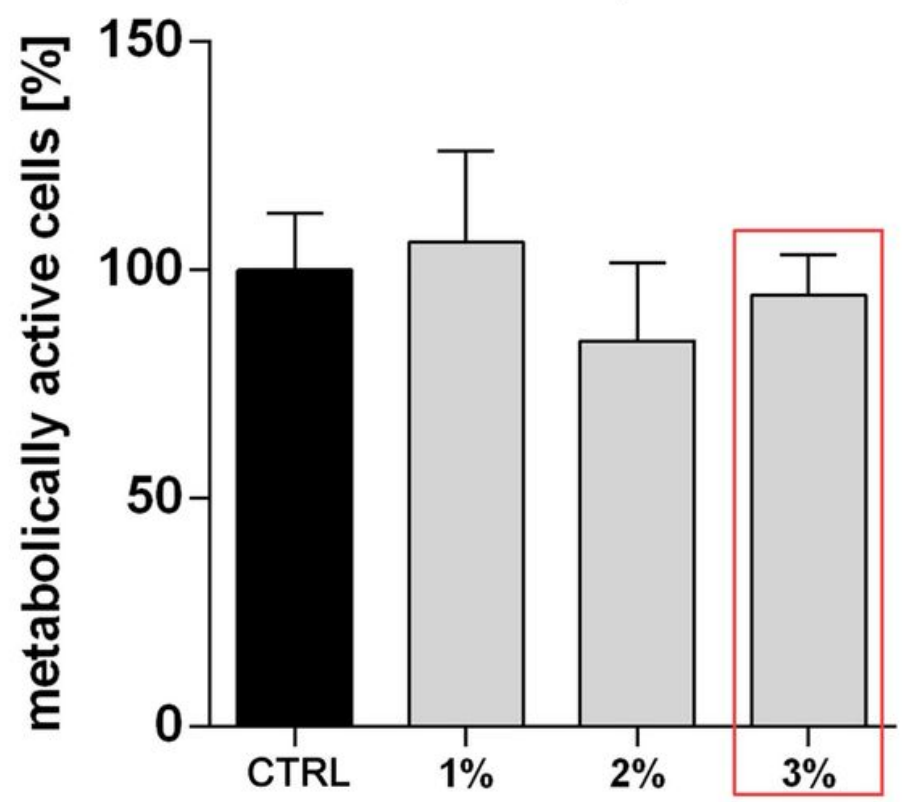

Phallus impudicus

Figure 1

Phallus impudicus-mediated changes in the metabolic activity of GC-1 spg (a) and GC-2 spd (b) cells. Cells were treated with different concentrations of Phallus impudicus alcohol extract (1-3\%) for $48 \mathrm{~h}$ and the MTT assay was performed. Dunnett's post hoc test with ANOVA was used to explore differences between control and test samples. A P-value of $<0.05$ was considered as statistically significant while bars indicate SD, $\mathrm{n}=3$; $* * \mathrm{P}<0.01$; no indication - no statistical significance.

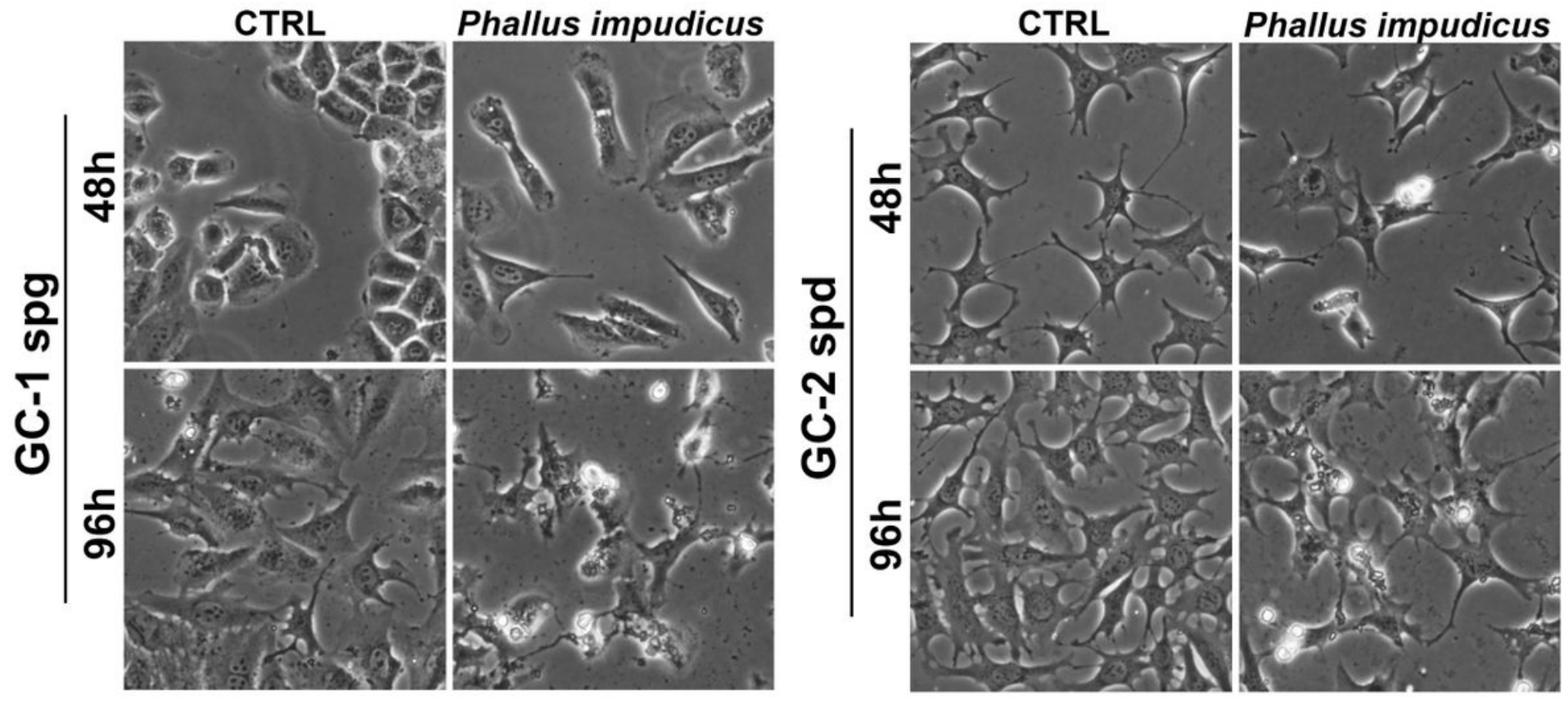

Figure 2 
Phallus impudicus-mediated changes in the morphology of the spermatogenic cells. Cells were treated with $3 \%$ Phallus impudicus alcohol extract for $96 \mathrm{~h}$ and the morphological abnormalities were controlled every 48h. Representative images are shown. Magnification of the objective lens 10x
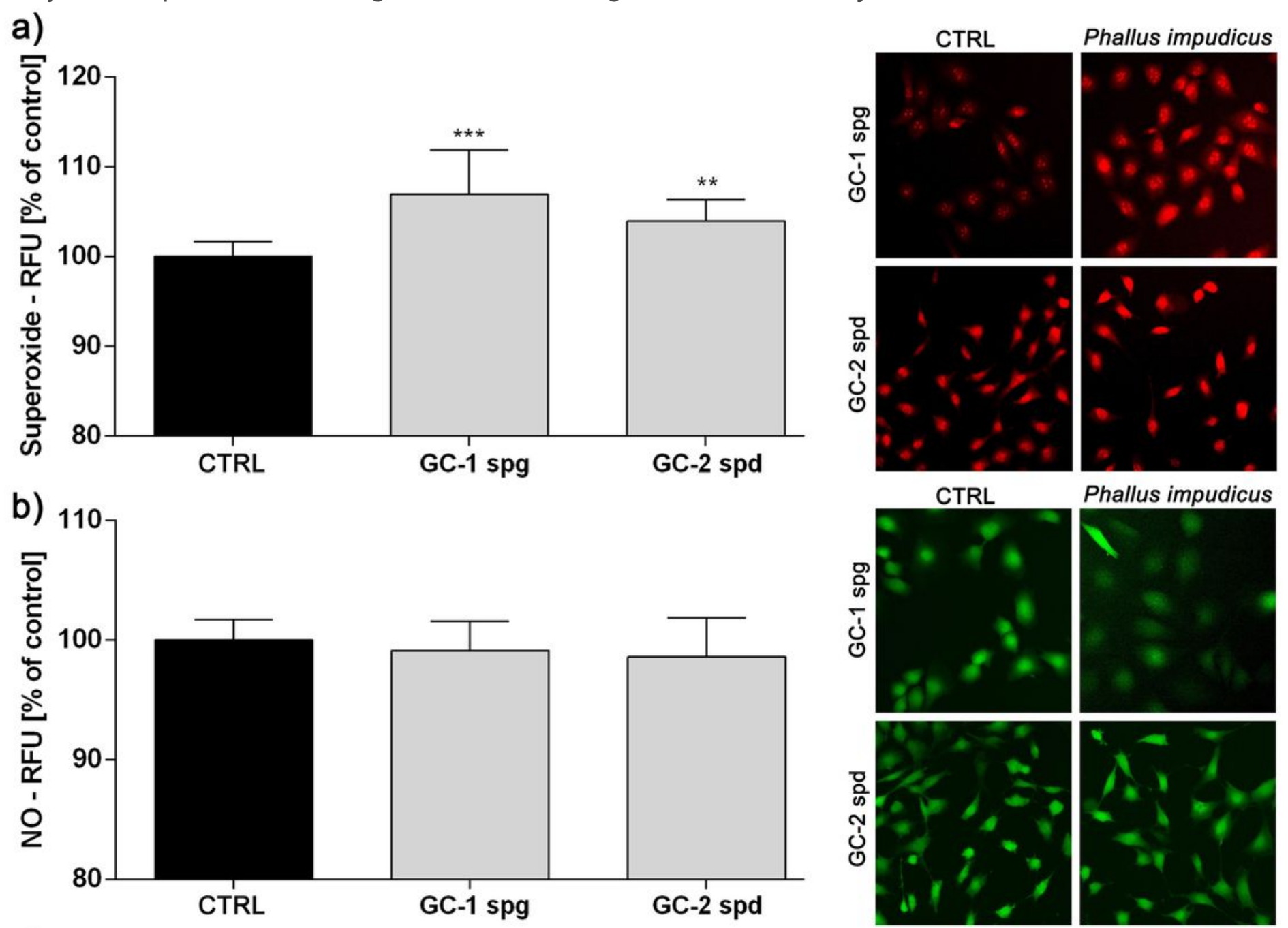

Phallus impudicus
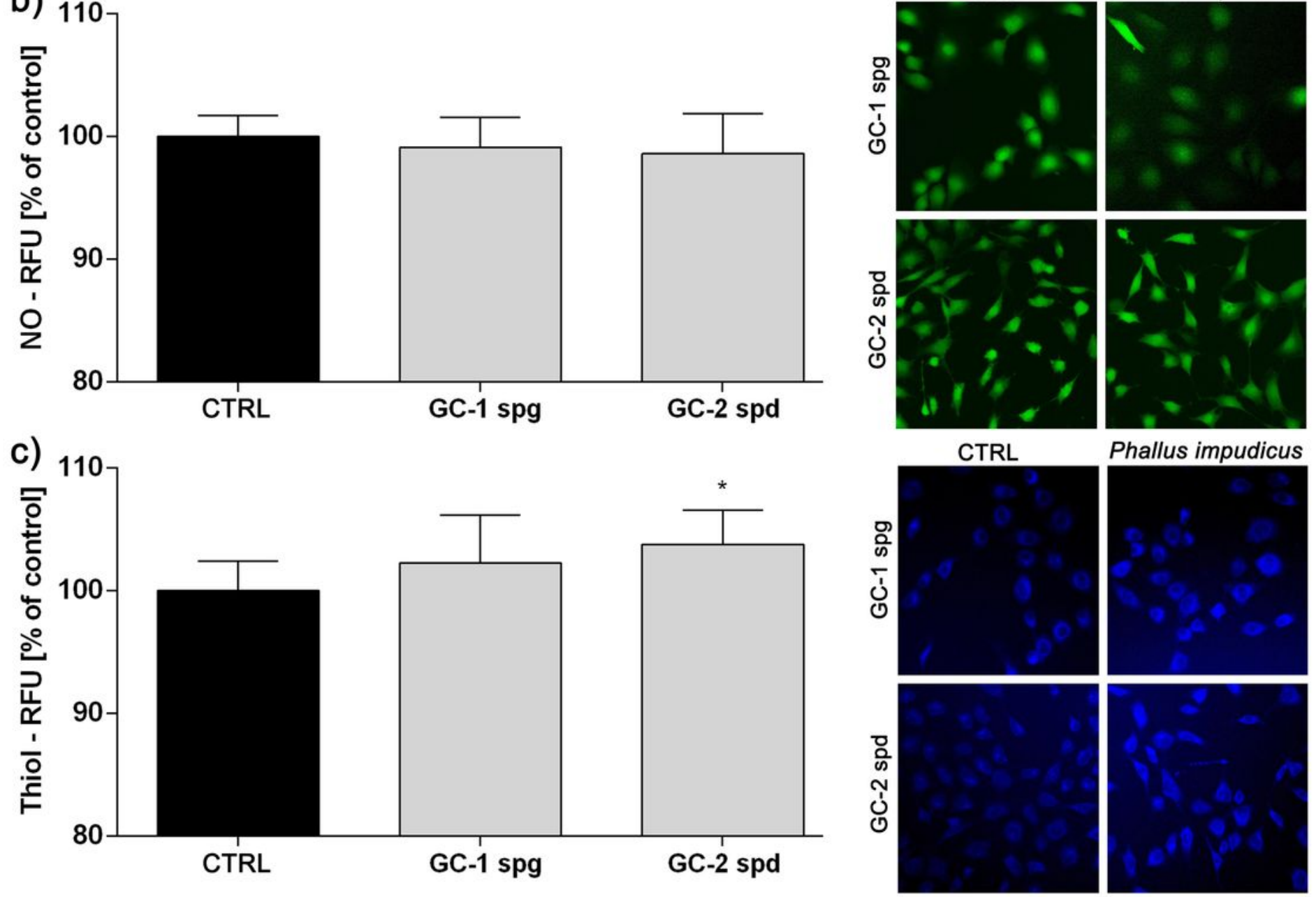

Phallus impudicus

\section{Figure 3}

Phallus impudicus-mediated changes in the redox homeostasis. Cells were treated with $3 \%$ Phallus impudicus alcohol extract for $48 \mathrm{~h}$ and the production of (a) reactive oxygen species, (b) nitric oxide, (c) 
thiol was measured. Representative images are shown. Magnification of the objective lens 10x. Red fluorescence (ROS), green (NO), blue fluorescence (Thiol). Dunnett's post hoc test with ANOVA was used to explore differences between control and test samples.A P-value of $<0.05$ was considered as statistically significant while bars indicate $S D, n=3$; ${ }^{* \star} P<0.001 ; * \star P<0.01 ; * P<0.05$; no indication - no statistical significance.

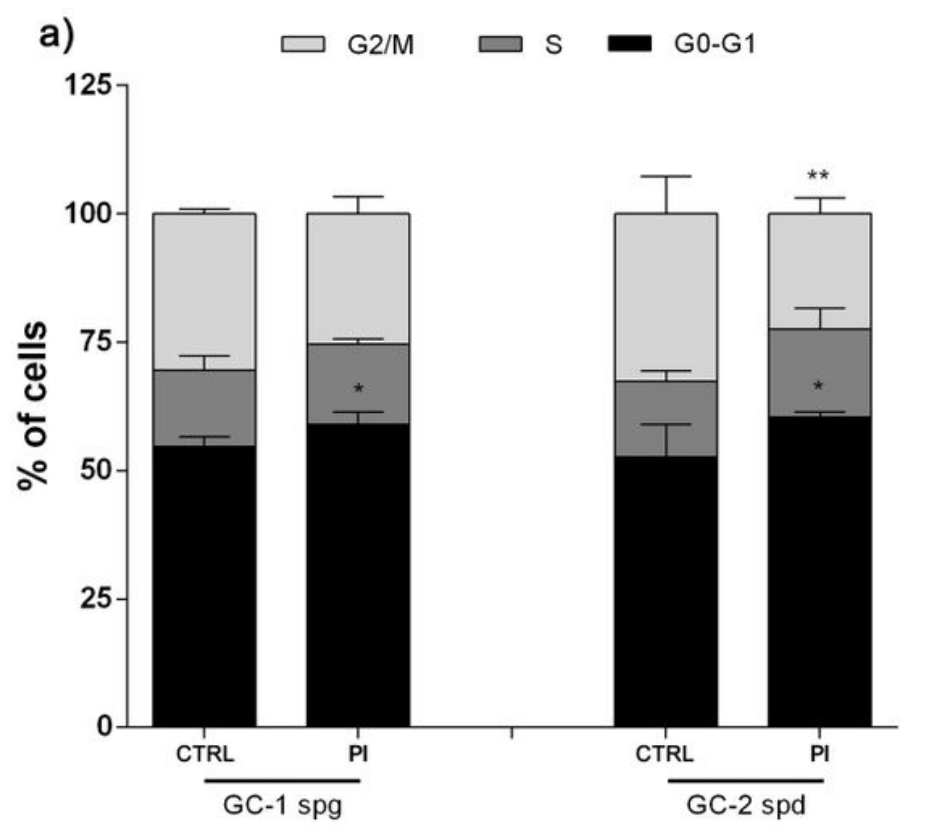

c)

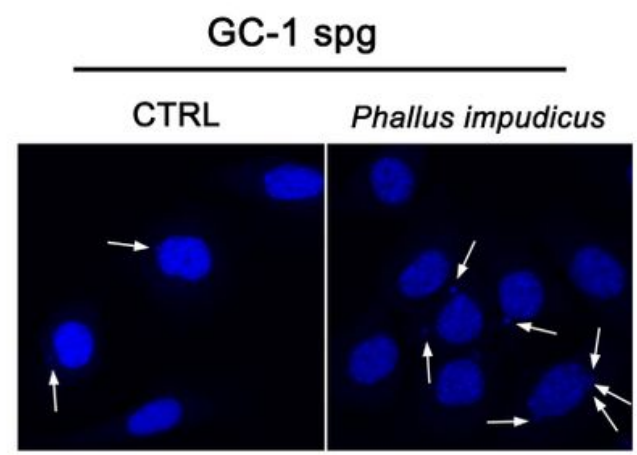

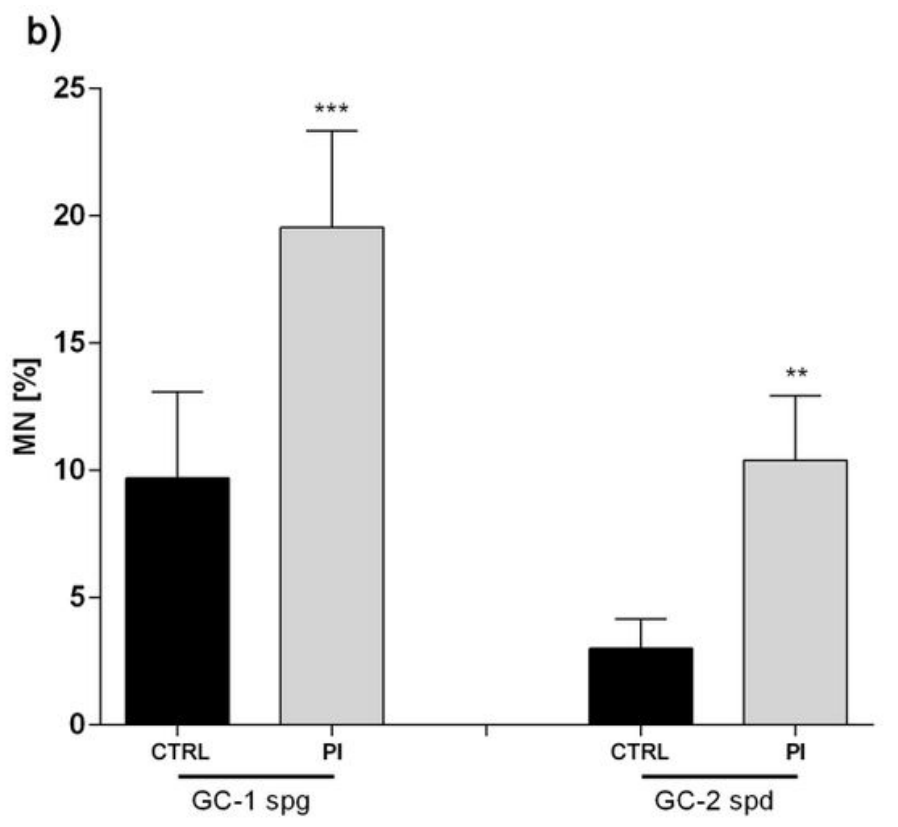

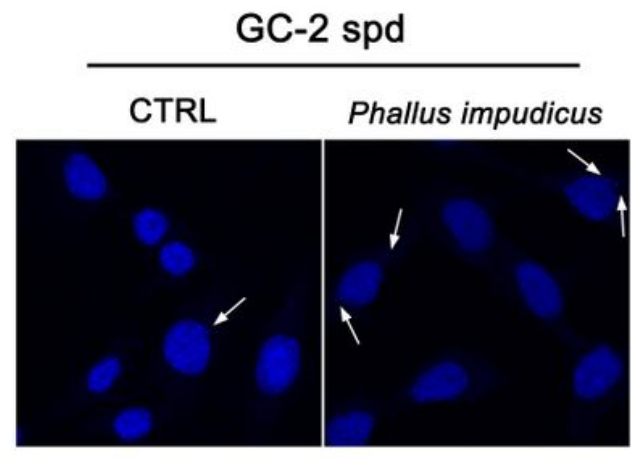

\section{Figure 4}

Phallus impudicus-mediated genotoxic events in spermatogenic cells. Cells were treated with $3 \%$ Phallus impudicus alcohol extract for $48 \mathrm{~h}$ and (a) cell cycle progression and (b) micronuclei formation were detected. Representative images are shown (c). Magnification of the objective lens 10x. Blue fluorescence $(\mathrm{MN})$. Dunnett's post hoc test with ANOVA was used to explore differences between control and test samples.A P-value of $<0.05$ was considered as statistically significant while bars indicate $S D, n=3$; $* \star * P$ $<0.001 ; * \star P<0.01 ; * P<0.05$; no indication - no statistical significance. 


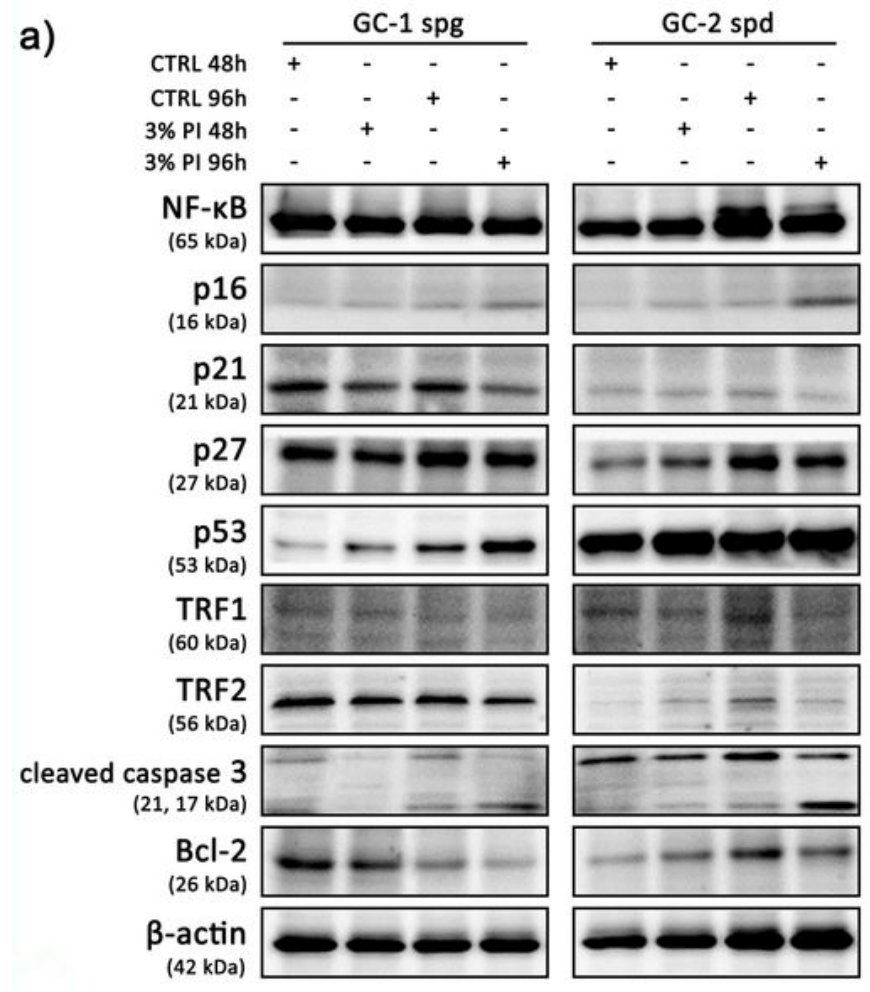

b)

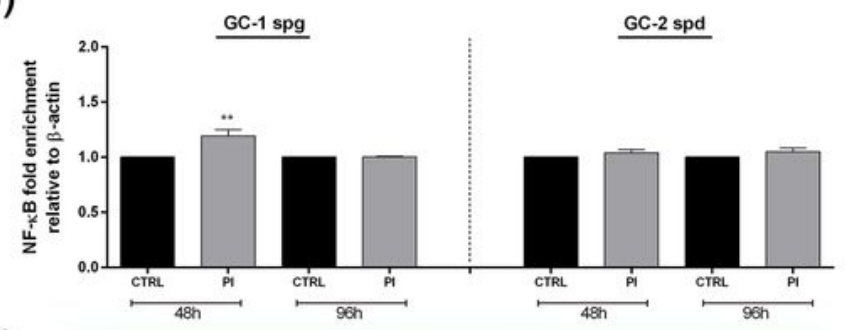

c)

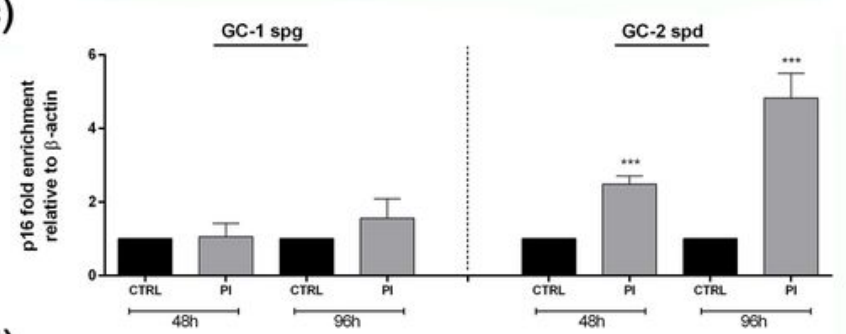

d)

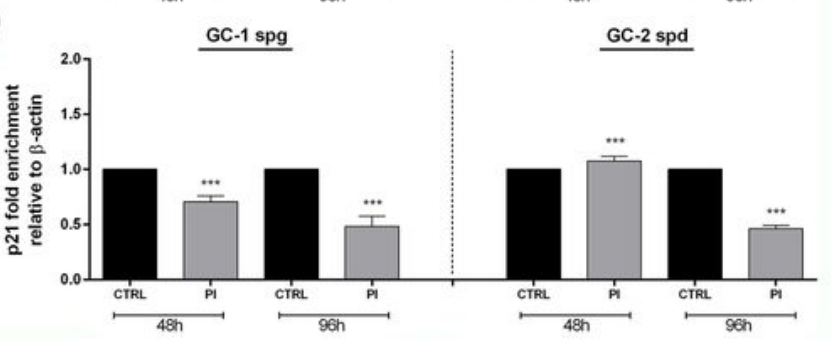

e)

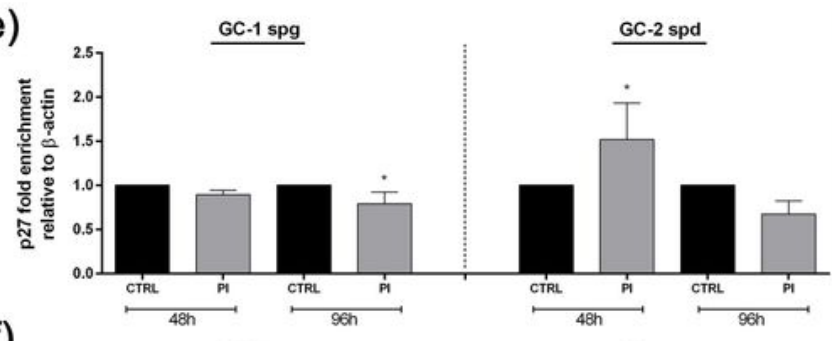

f)

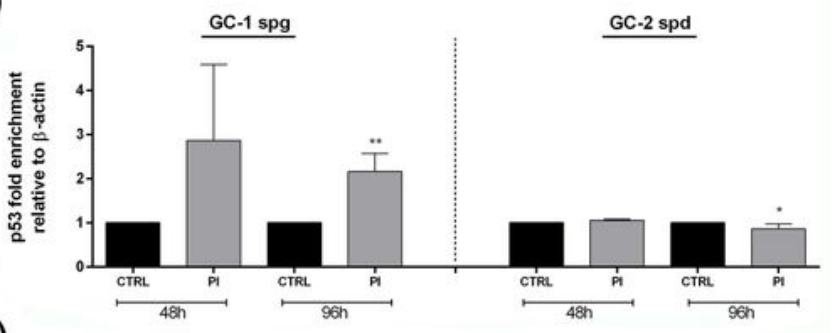

g)

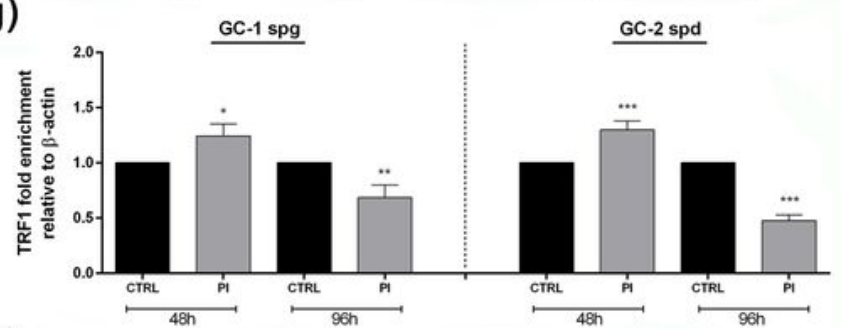

h)
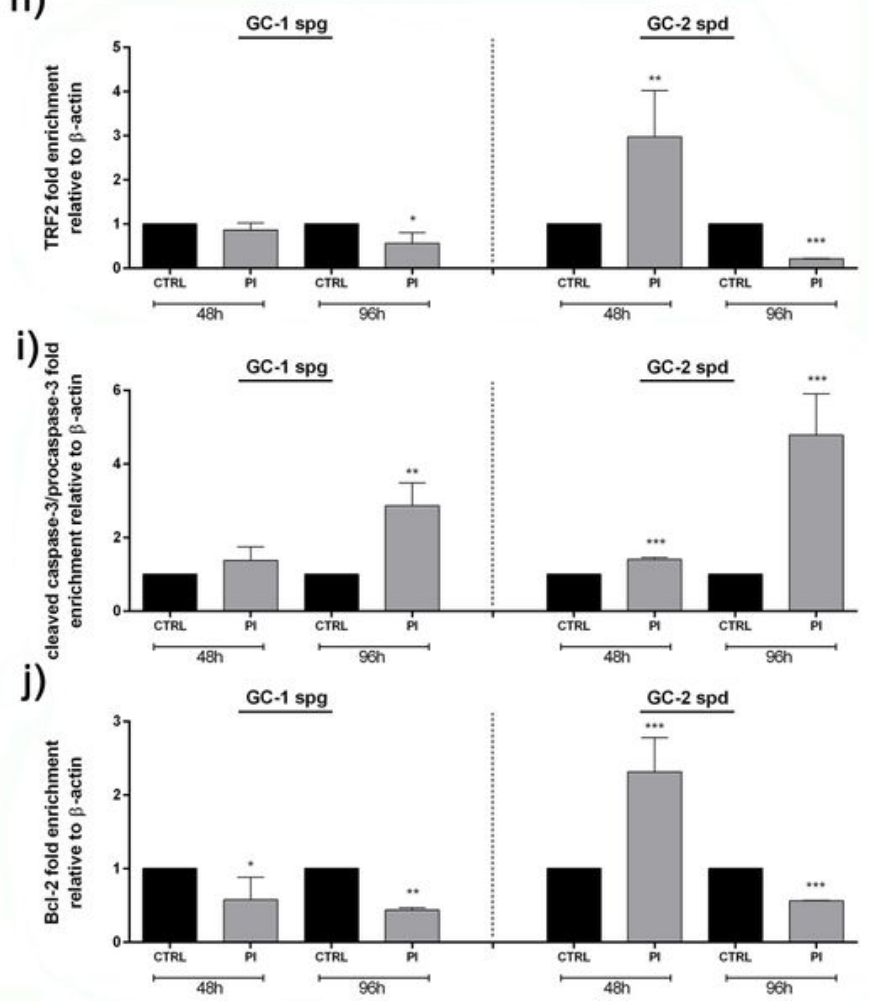

\section{Figure 5}

Phallus impudicus-mediated toxic effects in vitro in mechanistic terms. Cells were treated with $3 \%$ Phallus impudicus alcohol extract for 48 and $96 \mathrm{~h}$ and protein synthesis (b) NF-KB, (c) p16, (d) p21, (e) p27, (f) p53, (g) TRF1, (h) TRF2, (i) cleaved caspase-3, (j) Bcl-2 were monitored and measured. Representative images are shown (a). Dunnett's post hoc test with ANOVA was used to explore differences between control and test samples.A P-value of $<0.05$ was considered as statistically 
significant while bars indicate $S D, n=3 ; * \star * P<0.001 ; * \star P<<0.01 ; * P<0.05$; no indication - no statistical significance. 